\title{
An Empirical Investigation of the Prevalence of Osteoarthritis in South West Nigeria: A Population- Based Study
}

\author{
https://doi.org/10.3991/ijoe.v16i01.11554 \\ Aderonke Anthonia Kayode, Noah Oluwatobi Akande ${ }^{(\varpi)}$ \\ Landmark University, Kwara State, Nigeria \\ akande.noahelmu.edu.ng \\ Saheed O Jabaru \\ Al-Hikmah University, Ilorin, Nigeria \\ Tinuke Omolewa Oladele \\ University of Ilorin, Ilorin, Nigeria
}

\begin{abstract}
Today, Osteoarthritis remains the most prevalent chronic joint disease and a potentially incapacitating joint illness. It is an enduring health problem which cannot be cure though it can be managed. Osteoarthritis remains a serious public health problem because its burden is high, people who live with it have a greater risk of developing anxiety / or depression and if it is not properly managed, it can bring about disability as well as impairing quality of life. This paper presents a statistical correlation between the reported risk factors of Osteoarthritis and its prevalence in Nigeria. Statistical tests were performed to investigate if there is enough evidence for inferring that the risk factors for Osteoarthritis are true for the whole of Nigerian population.
\end{abstract}

Keywords - Osteoarthritis, Prevalence, Risk factors, Disability, Quality of life

\section{Introduction}

Osteoarthritis (OA) is known to be a degenerative joint disease of global public health importance. It is the most frequent musculoskeletal disorder associated with aging worldwide [1, 2, 3]. Pain is the major symptom experienced by most people who are living with OA [4, 5, 6,7]. OA is the end result of a damaged or lost articular cartilage. When the articular cartilage, which reduces friction between bones and also acts as shock, is broken down, it results in OA. The articular cartilage makes the movement of bones at their meeting point (joints) easier, thereby providing support and flexibility of joints [8]. It is a cushion, naturally place at the joint surface, which prevents two bones from rubbing each other at the point where they meet. However, when the cushion breaks down or damages, the underlying bones begin to rub each other and slowly wear and tear thereby causing pain, stiffness, swelling, restriction of movements in the attacked joint, to the extent that people affected may find it very 
difficult to carry out their daily tasks, and if not managed properly, they may not be productive any longer. In United States alone, over 30 million persons are living with $\mathrm{OA}$, also it has been reported to be the leading cause of permanent disability among her elderly population [9]. OA also causes reduced function and disability; some people are no more productive, that is, they are no longer able to carry out their daily tasks or jobs. OA was adjudged to be a chronic musculoskeletal condition accountable for limited activity (particularly walking), reduced participation and impaired quality of life (QoL) [10]. OA is a national tragedy because it imposes a huge financial burden through wage loss along with the cost of medications [11]. In addition, it has severely endangered the lives and livelihoods of many people worldwide [12] thereby causing impaired QoL [13]. This tragedy is exacerbated owing to the fact that no permanent treatment exists currently for OA, the available therapy only seeks to relieve symptoms, improve joint mobility and function, and improving the QoL of individual living with it $[13,14,15]$. To this end, there is a need to create awareness in Nigeria that OA being a serious public health problem, if not properly managed can lead to permanent disability, and to publish the various ways through which it can be prevented with the aim of aiding policy making. In this paper, effortful attempt has been made to investigate the relationship between prevalence of OA and its root risk factors amongst Nigerians and to create appropriate awareness for this QoL threatening syndrome.

\subsection{Epidemiology of osteoarthritis}

Osteoarthritis is the most common type of arthritis. it is often caused by wear and tear on a joint over a lifetime. It is mostly found in knee, spine, hip and hand [16]. OA causes cartilage to undergo a slow damage due to stiffness developed by losing the elasticity, thereby causing gradual erosion. This erosion causes ligaments to experience stretching that initiates the pain, therefore, it no longer can act as a proper shock absorber. The outcome is that the bones start rubbing with each other adding agony and suffering. Initially, the symptoms advance slowly but worsens with time causing inflammation and creating more harm to the joint. Patients feel pain during and after the joint- movement. There is an aching sensation at the joints if the patient tries to move suddenly which usually occurs when patients wake up in the morning. In most cases the development of stiffness is a common indication [17]. It has been ascertained that the disease advances with age $[2,18,19]$. Along with its progression, patients lose flexibility and feel irritating sensation while flexing the joints. As a symptom, hard lumps or bone spikes appear at the joints under attack [20]. OA, though most often found in the knees, is also found in the hands, hips and spine foot [21]. OA is an enduring illness, though it can be managed but do not have a permanent cure as such not everybody living with OA reports its incidence in the hospital.

\subsection{Clinical characteristics of osteoarthritis}

Osteoarthritis can damage any joint in the human body; however, its occurrence is common in "usage-related" joints, especially, the, knees, hips, spine and hands. The 
most common symptoms of OA are morning stiffness, usage-related pain, and restriction of locomotors [22]. As stated earlier OA is a progressive disease. The clinical features of OA vary from early stage to the advanced stage. These features may include: short-lived morning stiffness, restriction of locomotors, loss of flexibility, grating sensation and pain at extremes of movement in early stage. More severe OA is characterized by enlargement of bone, crepitus and reduced range of movement while rest pain, night pain, muscle wasting, bone spur and deformity suggest advanced OA. Symptoms and signs of swelling or inflammation are very rare in people living with OA unlike other forms of arthritis.

\subsection{Risk factors of osteoarthritis}

Some risk factors of OA are socio-demographic related (age, gender, and occupation), obesity, genetics and previous injury. It was affirmed that with aging, OA is inevitable, as its prevalence increases amongst the aged population of developing and developed countries. As such, age is considered one of the primary risk factors of OA $[3,17,23,24,25]$. Several studies have reported that gender is an important factor to be mentioned in the discourse of incidence of OA. OA is more prevalent in females than in their male counterparts [21, 26, 27]. Genetic factor has been considered a very strong risk factor of OA [27, 29]. It has been reported that family history is also a powerful contributing factor of OA [29, 30]. However, there is substantial correlation between genetics and OA [31]. History of joint injury is another risk factor of OA. Previous joint injury could be from a fall, a vehicle accident, military injury, sport or any form of physical injury to a joint. Subjects who have one time or the other experience joint injury are more likely to develop OA [32]. Previous studies showed that persons whose occupations involve extreme pressure and joint activity are likely to develop OA [30, 12]. Daily lifting and carrying of loads are strong determinants of KOA. Individuals whose physical work load are heavy or include regular climbing of stairs, kneeling, crawling, bending and rhythmic movement are liable to develop OA [33]. However, the fact that individuals who are obese (i.e. whose BMI > 29.9kg/m2) are at greater risk of developing KOA [34]. Obesity is a clear risk for developing OA because it overwhelms the joints, such as the knee, with increased load, which in turn increases stress and could possibly speed up the breakdown of the joint cartilage [35].

\section{Materials and Methods}

In this study, social survey was carried out to obtain relevant information regarding the awareness and prevalence of OA from respondents. Questionnaire was the research instrument used to gather statistically useful information regarding the subject matter because with it, it is relatively easy, fast and economical to reach large number of people. A pool of 30 semi-structured questions was developed. The questionnaire was divided into three sections, namely: Demographic and social characteristics of the Respondents, Symptoms of OA, and Treatment and Medication of OA. Experts (Rheumatologists and Physiotherapist) and several lay persons were asked to appraise 
the questions for face validity, breadth of coverage and content validity. One thousand eight hundred (1800) questionnaires were personally administered to Nigerians aged eighteen (18) and above, from different walks of life. The study was carried out in the urban and rural areas of South West Nigeria (which comprises six states namely: Ekiti, Lagos, Ogun, Ondo, Osun and Oyo) between January 2018 and February 2019.

Six research hypotheses were formulated and tested to establish whether or not there is a significant relationship between risk factors and incidence of OA. The major risk factors of OA have been reported to include socio-demographic characteristics (age, gender and occupation), genetics, body mass index (BMI), and previous joint injury $[21,24]$. BMI is the value got from the height and weight of an individual; it is calculated by dividing weight in kilograms $(\mathrm{kg})$ by the square of height in metres $(\mathrm{m})$, universally expressed as $\mathrm{kg} / \mathrm{m} 2$. Statistical Package for Social Sciences (SPSS) for windows was used for data analysis, chi-square test was employed to analyze data and test the association between each of the risk factors and incidence of OA. The correlation coefficient ( $r$ ) was also calculated in order to determine the strength of the relationship between each of the risk factors and OA prevalence. Descriptive analysis, which produces frequency tables and charts that displayed both the numbers and percentages of cases for each observed value of variables, was also carried out.

\subsection{Research hypotheses}

A hypothesis is referred to as a mere assumption based on inadequate proof that needs further investigation and experiment in order to be proved or disproved. To ascertain whether a hypothesis is true or false, it must be subjected to further testing. Testing a hypothesis begins by taking two hypotheses called the null hypothesis and the alternative hypothesis into consideration. These hypotheses include conflicting perspectives.

In this paper we formulate six hypotheses to test whether there are significant relationships between the risk factors of OA and its prevalence.

Hypothesis 1: $\mathrm{H}_{0}$ : No statistically-significant relationship exists between age and the incidence of $\mathrm{OA}$

$\mathrm{H}_{1}$ : A statistically-significant relationship does exist between age and the incidence of OA

Hypothesis 2: $\mathrm{H}_{0}$ : No statistically-significant relationship exists between occupation and incidence of $\mathrm{OA}$

$\mathrm{H}_{1}$ : A statistically-significant relationship does exist between occupation and the incidence of $\mathrm{OA}$

Hypothesis 3: $\mathrm{H}_{0}$ : No statistically-significant relationship exists between gender and the incidence of $\mathrm{OA}$

$\mathrm{H}_{1}$ : A statistically-significant relationship does exist between gender and the incidence of OA

Hypothesis 4: $\mathrm{H}_{0}$ : No statistically-significant relationship exists between previous joint injury and the incidence of OA

$\mathrm{H}_{1}$ : A statistically-significant relationship does exist between previous joint injury and the incidence of $\mathrm{OA}$ 
Hypothesis 5: $\mathrm{H}_{0}$ : No statistically-significant relationship exists between BMI and the incidence of $\mathrm{OA}$

$\mathrm{H}_{1}$ : A statistically-significant relationship does exist between BMI and the incidence of OA

Hypothesis 6: $\mathrm{H}_{0}$ : No statistically-significant relationship exists between genetics and the incidence of $\mathrm{OA}$

$\mathrm{H}_{1}$ : A statistically-significant relationship does exist between genetics and the incidence of OA.

\subsection{Criteria for acceptance and rejection of hypothesis}

In this study the decisive factors used either to accept or to reject the null hypothesis are as follows:

If $\chi_{\text {cal }}^{2}>\chi_{\text {tab }}^{2}$, the null hypothesis is rejected otherwise the null hypothesis is accepted

If $\mathrm{p}<=\alpha$, the null hypothesis is rejected, otherwise it is accepted

Where $\alpha$ is the level of significance which is set to be $0.05(\alpha=0.05)$ and $p$ is the probability that indicate the strength of evidence for a null hypothesis.

\section{Results and Discussion}

This section discusses the results obtained from this study.

\subsection{Socio demographic characteristics of the respondents}

A total of 1800 questionnaires were administered. Only 1520 consisting 700 males (46.1\%) and 820 females (53.6\%) questionnaire were analyzed, the remaining ones (280) were either incomplete or not returned. Table 1 shows the socio-demographic characteristics of the respondents. Age distribution of the respondents showed the lowest fraction, $278(18.3 \%)$ in the above 60years' age group while in the occupationwise distribution of the respondents, trader/craftsman/farmer has the highest fraction $296(19.5 \%)$.

Table 1. Respondents Socio-demographic characteristics ( $\mathrm{n}=1520)$

\begin{tabular}{|l|c|}
\hline \multicolumn{1}{|c|}{ Socio-demographic Characteristic } & Number (\%) \\
\hline Male & $700(46.1)$ \\
\hline Female & $820(53.9)$ \\
\hline \multicolumn{2}{|c|}{ Age Group (years) } \\
\hline $18-30$ & $290(19.1)$ \\
\hline $31-40$ & $300(19.7)$ \\
\hline $41-50$ & $325(21.4)$ \\
\hline $51-60$ & $327(21.5)$ \\
\hline Above 60 & $278(18.3)$ \\
\hline
\end{tabular}




\begin{tabular}{|l|c|}
\hline \multicolumn{2}{|c|}{ Respondents } \\
\hline Professional & $229(15.1)$ \\
\hline Technician and Manual & $268(17.6)$ \\
\hline Trader / craftsman / Farmer & $296(19.5)$ \\
\hline Housewife / unemployed & $203(13.4)$ \\
\hline Retiree & $271(17.8)$ \\
\hline Students & $253(16.6)$ \\
\hline
\end{tabular}

\subsection{Prevalence of osteoarthritis}

Table 2 showed the prevalence of OA. It can be seen from the table that a larger percentage $(67.1 \%)$ of Nigerian population is living with OA with $50.6 \%$ males and $81.2 \%$. This shows that prevalence of $\mathrm{OA}$ is higher among females than males as clearly illustrated in Figure 1. Considering the age distribution of the respondents (see Table 2), it can be seen that oldest population, adults whose age > 60 years $(96.0 \%)$ are mostly plagued with OA (see Fig. 2). This correlates with the work of reported in [17] where age was reported to be the most prominent risk factor for OA.

Table 2. Prevalence of Osteoarthritis by Risk Factors

\begin{tabular}{|c|c|c|c|}
\hline Risk Factors & $\begin{array}{c}\text { No. of Respondent Sur- } \\
\text { veyed }\end{array}$ & $\begin{array}{l}\text { Individual with } \\
\text { Osteoarthritis }\end{array}$ & Prevalence $(\%)$ \\
\hline \multicolumn{4}{|l|}{ Gender } \\
\hline Male & 700 & 354 & 50.6 \\
\hline Female & 820 & 666 & 81.2 \\
\hline Total & 1520 & 1020 & 61.7 \\
\hline \multicolumn{4}{|c|}{ Age (years) } \\
\hline $18-30$ & 290 & 68 & 23.4 \\
\hline $31-40$ & 300 & 98 & 32.7 \\
\hline $41-50$ & 325 & 280 & 86.2 \\
\hline $51-60$ & 327 & 307 & 93.9 \\
\hline Above 60 & 278 & 267 & 96.0 \\
\hline Total & 1520 & 1020 & 67.1 \\
\hline \multicolumn{4}{|c|}{ Respondents } \\
\hline \multicolumn{4}{|l|}{ Occupation } \\
\hline Professionals & 229 & 189 & 82.5 \\
\hline Technicians/Manual & 268 & 243 & 90.7 \\
\hline Traders/ Craftsmen/Farmers & 296 & 253 & 85.5 \\
\hline Housewives/Unemployed & 203 & 101 & 49.8 \\
\hline Retirees & 271 & 181 & 66.8 \\
\hline Students & 253 & 53 & 20.9 \\
\hline Total & 1520 & 1020 & 67.1 \\
\hline \multicolumn{4}{|l|}{ BMI $\left(\mathrm{kg} / \mathrm{m}^{2}\right)$} \\
\hline Underweight: $<18.5$ & 335 & 189 & 56.4 \\
\hline Normal weight: $18.0-24.9$ & 398 & 258 & 64.8 \\
\hline Overweight: 25.0-29.9 & 361 & 247 & 68.4 \\
\hline Class I Obesity: $30.0-34.9$ & 239 & 178 & 74.5 \\
\hline Class II Obesity: 35.0-39.9 & 122 & 95 & 77.9 \\
\hline
\end{tabular}


Paper-An Empirical Investigation of the Prevalence of Osteoarthritis in South West Nigeria...

\begin{tabular}{|c|c|c|c|}
\hline Class III Obesity: $\geq 40.0$ & 65 & 53 & 81.5 \\
\hline & 1520 & 1020 & 67.1 \\
\hline \multicolumn{4}{|c|}{\begin{tabular}{|c|} 
History of OA/Hereditary \\
\end{tabular}} \\
\hline Yes & 305 & 265 & 86.9 \\
\hline No & 1215 & 755 & 62.1 \\
\hline Total & 1520 & 1020 & 61.7 \\
\hline \multicolumn{4}{|l|}{ Previous Injury } \\
\hline Yes & 323 & 288 & 89.2 \\
\hline \multirow[t]{2}{*}{ No } & 1197 & 732 & 61.2 \\
\hline & 1520 & 1020 & 61.7 \\
\hline
\end{tabular}

* Obtained by dividing the weight $(\mathrm{kg})$ of the Respondent by the square of his/her height $(\mathrm{m})$

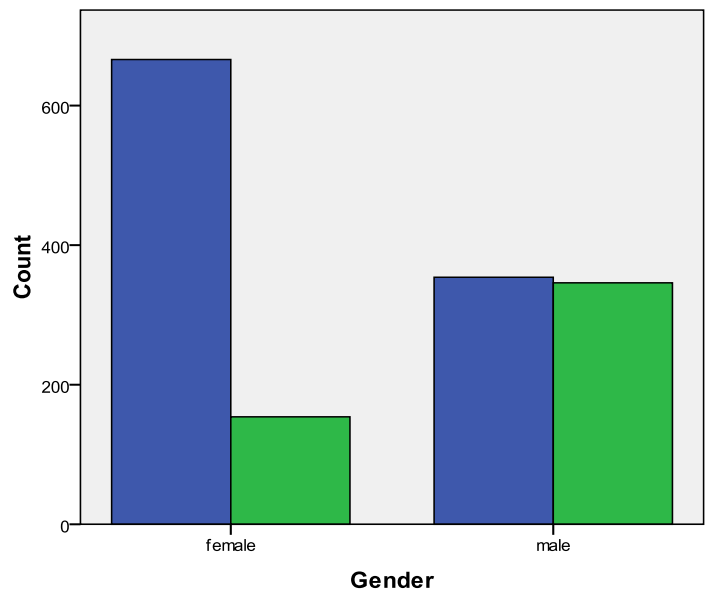

OA Status

$\square$ with OA

Fig. 1. Osteoarthritis Status by Gender

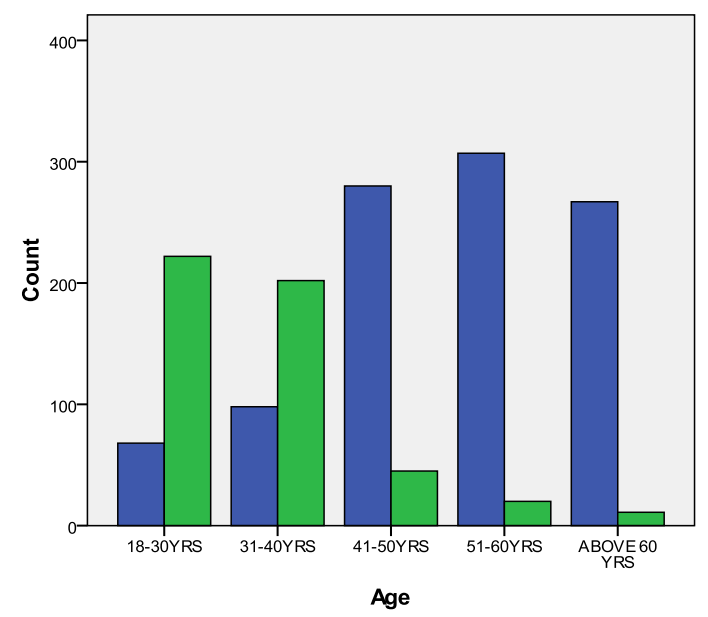

Fig. 2. Osteoarthritis Status by Age 
From Table 2, Occupation distribution shows that prevalence of OA is not that pronounced among housewives/unemployed and students $(49.8 \%$ and $20.9 \%$ respectively). This shows that $\mathrm{OA}$ is prevalent among the employed population. $86.9 \%$ of those who have history of OA in their families are actually living with $\mathrm{OA}$; this indicates that OA is more prevalence among people who have history of OA in their families as seen in Fig. 3. This indicates that hereditary is also one of the key factors of OA.

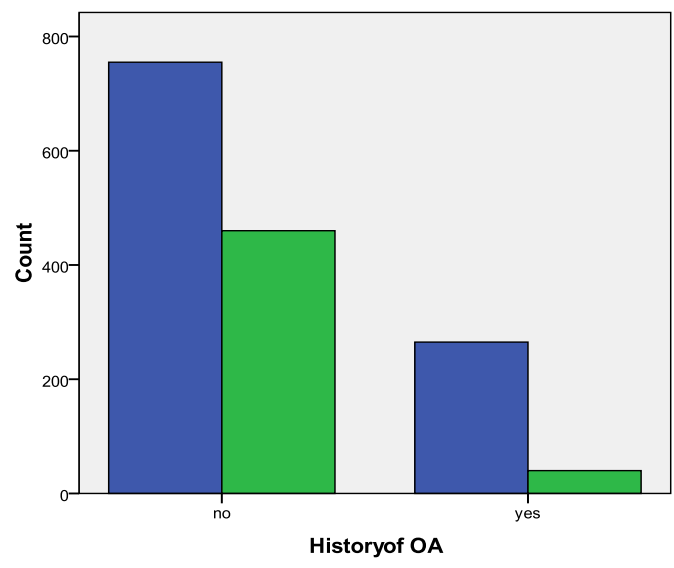

Fig. 3. Osteoarthritis Status by Hereditary

In the like manner, $89.2 \%$ of the people who had experience previous injury are living with $\mathrm{OA}$ as illustrated in both Table 2 and Fig. 4; this makes previous injury a key risk factor for Osteoarthritis.

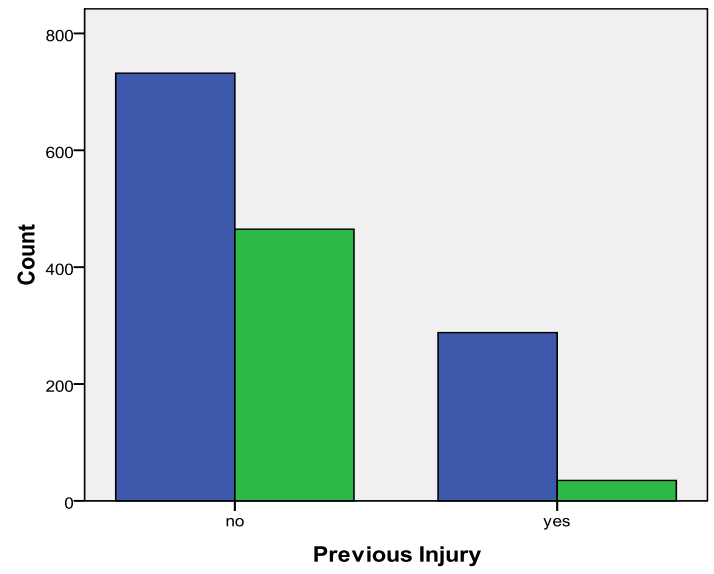

OA Status

$\square$ with $O A$

Previous Injury

Fig. 4. Osteoarthritis Status by Previous Injury 
The study shows that respondents who are obese (Class I, Class II or Class III) are more plagued with OA than individual respondents who are underweight, have normal weight or who are overweight this can be seen in both Table 2 and Fig. 5.

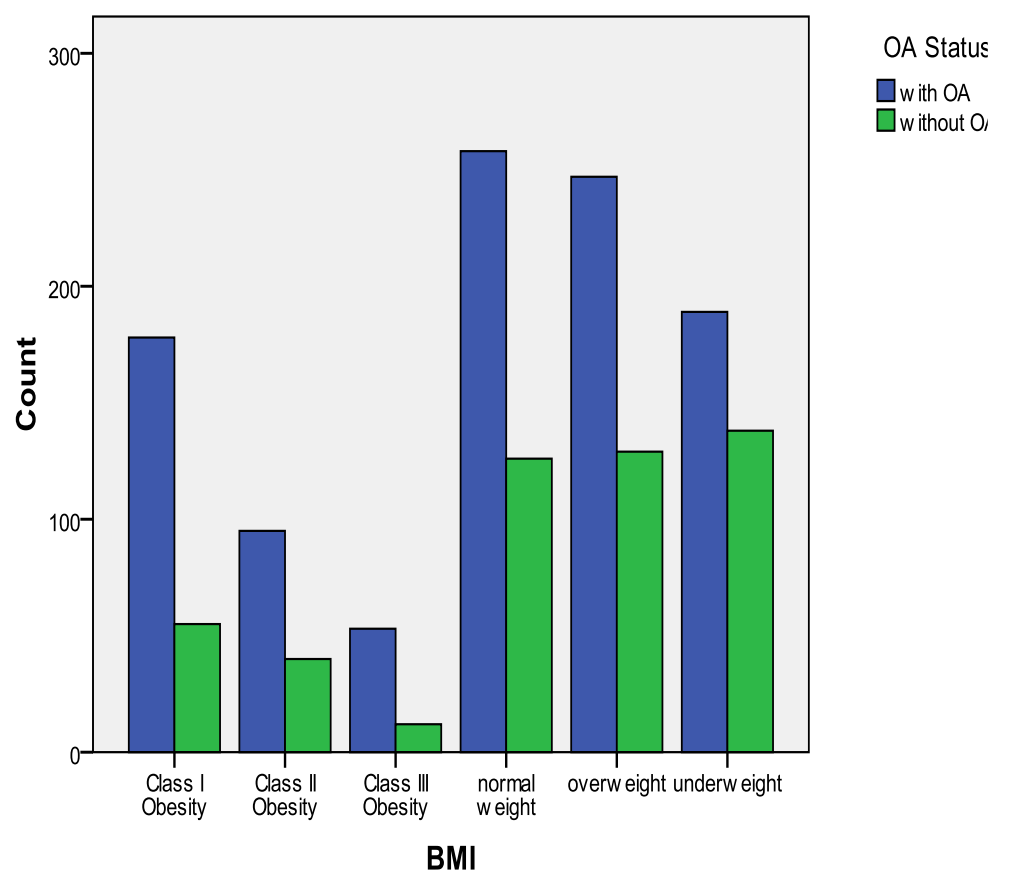

Fig. 5. Osteoarthritis Status by BMI

\subsection{Test of correlation between socio-demographic variables and prevalence of osteoarthritis}

Result of the test of correlation between socio-demographic characteristics (age, gender and occupation) and prevalence of OA is presented in Table 3. The result shows that there is a positive and strong correlation between age and prevalence of $\mathrm{OA}(\mathrm{r}=0.67)$, positive and moderate relationship between occupation and prevalence of OA $(r=0.52)$ while gender has a positive and weak relationship with $\mathrm{OA}(\mathrm{r}=$ 0.33 ). The results of chi-square test on the significance of association between these socio-demographic variables and OA prevalence showed that there are sufficient evidences to conclude that there is significant relationship between them. For these variables, $\chi 2 \mathrm{cal}>\chi 2 \mathrm{tab}, \mathrm{p}=0.000$, this mean $\mathrm{p}<\alpha$ which is set at 0.05 significant level. 


\subsection{Test of correlation between other risk factors and prevalence of osteoarthritis}

Apart from social-demographic variables, previous injury, heredity and BMI have been reported to be risk factors for OA. The result of test of correlation carried out separately between BMI, previous injury and heredity, and prevalent of OA are presented Tables 4, 5 and 6 respectively. Tables 4, 5, 6 revealed that history of previous injury, hereditary and BMI correlates with prevalence of OA $(r=0.24,0.21$ and 0.14 respectively). In the like manner, it can be concluded from tables 4, 5, 6 that significant relationships exist between prevalence of OA and each of the risk factors $(\mathrm{p}=$ 0.000 from the Tables). The results of chi-square test on the significance of association between these risk factors and OA prevalence showed that there are sufficient evidences to conclude that there is a significant relationship between them. For these variables, $\chi 2 \mathrm{cal}>\chi 2 \mathrm{tab}, \mathrm{p}=0.000$, this mean $\mathrm{p}<\alpha$ which is set at 0.05 significant level. There is strong evidence that all the null hypotheses are invalid.

Table 3. Association between Socio-demographic Characteristics and the Prevalence of Osteoarthritis

\begin{tabular}{|c|c|c|c|c|c|c|c|c|}
\hline \multirow{2}{*}{$\begin{array}{c}\text { Socio-demographic character- } \\
\text { istics }\end{array}$} & \multicolumn{3}{|c|}{ Number $(\%)$} & \multirow{2}{*}{ df } & \multirow{2}{*}{$* \mathbf{r}$} & \multirow{2}{*}{$\chi_{\text {cal }}^{2}$} & \multirow{2}{*}{$\chi_{\text {tab }}^{2}$} & \multirow{2}{*}{$\mathbf{P}$} \\
\hline & Yes & No & Total & & & & & \\
\hline Male & $354(50.6)$ & $346(49.4)$ & $700(100)$ & \multirow{2}{*}{1} & \multirow{2}{*}{0.33} & \multirow{2}{*}{160.69} & \multirow{2}{*}{3.84} & \multirow{2}{*}{0.000} \\
\hline Female & $666(81.2)$ & $154(18.8)$ & $820(100)$ & & & & & \\
\hline Total & $1020(67.1)$ & $500(32.9)$ & $1520(100)$ & & & & & \\
\hline $18-30$ & $68(23.4)$ & $222(76.6)$ & $290(100)$ & \multirow{5}{*}{4} & \multirow{5}{*}{0.67} & \multirow{5}{*}{676.69} & \multirow{5}{*}{9.49} & \multirow{5}{*}{0.000} \\
\hline $31-40$ & $98(32.7)$ & $202(67.3)$ & $300(100)$ & & & & & \\
\hline $41-50$ & $280(86.2)$ & $4513.8)$ & $325(100)$ & & & & & \\
\hline $51-60$ & $307(93.9)$ & $20(6.1)$ & $327(100)$ & & & & & \\
\hline Above 60 & $267(96.0)$ & $11(4.0)$ & $278(100)$ & & & & & \\
\hline Total & $1020(67.1)$ & $500(32.9)$ & $1520(100)$ & & & & & \\
\hline Professional & $189(82.5)$ & $40(17.5)$ & $229(100)$ & \multirow{6}{*}{5} & \multirow{6}{*}{0.52} & \multirow{6}{*}{409.24} & \multirow{6}{*}{11.07} & \multirow{6}{*}{0.000} \\
\hline Technician/Manual & $243(90.7)$ & $25(9.3)$ & $268(100)$ & & & & & \\
\hline Trader/ Craftsman/Farmer & $253(85.5)$ & $43(14.5)$ & $296(100)$ & & & & & \\
\hline Housewife/ Unemployed & $101(49.8)$ & $102(50.2)$ & $203(100)$ & & & & & \\
\hline Retiree & $181(66.8)$ & $90(33.2)$ & $271(100)$ & & & & & \\
\hline Student & $53(20.9)$ & $200(79.1)$ & $253(100)$ & & & & & \\
\hline Total & $1020(67.1)$ & $500(32.9)$ & $1520(100)$ & & & & & \\
\hline
\end{tabular}

Table 4. Association between Previous Injury and the Prevalence of Osteoarthritis

\begin{tabular}{|c|c|c|c|c|c|c|c|c|}
\hline \multirow{2}{*}{ Previous Injury } & \multicolumn{3}{|c|}{ Number (\%) } & \multirow{2}{*}{ df } & \multirow{2}{*}{$* \mathbf{r}$} & \multirow{2}{*}{$\chi_{\text {cal }}^{2}$} & \multirow{2}{*}{$\chi_{\text {tab }}^{2}$} & \multirow{2}{*}{$\mathbf{P}$} \\
\hline & Yes & No & Total & & & & & \\
\hline Yes & $288(89.2)$ & $35(10.8)$ & $323(100)$ & \multirow{2}{*}{1} & \multirow{2}{*}{0.24} & \multirow{2}{*}{90.41} & \multirow{2}{*}{3.84} & \multirow{2}{*}{0.000} \\
\hline No & $732(61.2)$ & $465(38.8)$ & 1197(100) & & & & & \\
\hline Total & $1020(67.1)$ & $500(32.9)$ & $1520(100)$ & & & & & \\
\hline
\end{tabular}


Table 5. Association between Hereditary and the Prevalence of Osteoarthritis

\begin{tabular}{|c|c|c|c|c|c|c|c|c|}
\hline \multirow{2}{*}{$\begin{array}{c}\text { History of } \\
\text { Osteoarthritis }\end{array}$} & \multicolumn{3}{|c|}{ Number (\%) } & \multirow{2}{*}{ df } & \multirow{2}{*}{$* \mathbf{r}$} & \multirow{2}{*}{$\chi_{\text {cal }}^{2}$} & \multirow{2}{*}{$\chi_{\text {tab }}^{2}$} & \multirow{2}{*}{$\mathbf{P}$} \\
\hline & Yes & No & Total & & & & & \\
\hline Yes & $265(86.9)$ & $40(13.1)$ & $305(100)$ & \multirow{2}{*}{1} & \multirow{2}{*}{0.21} & \multirow{2}{*}{67.63} & \multirow{2}{*}{3.84} & \multirow{2}{*}{0.000} \\
\hline No & $755(62.1)$ & $460(37.9)$ & $1215(100)$ & & & & & \\
\hline Total & $1020(67.1)$ & $500(32.9)$ & $1520(100)$ & & & & & \\
\hline
\end{tabular}

Table 6. Association between BMI and the Prevalence of Osteoarthritis

\begin{tabular}{|c|c|c|c|c|c|c|c|c|}
\hline \multirow{2}{*}{ BMI $\left(\mathbf{k g} / \mathbf{m}^{2}\right)$} & \multicolumn{3}{|c|}{ Number (\%) } & \multirow{2}{*}{ df } & \multirow{2}{*}{$* \mathbf{r}$} & \multirow{2}{*}{$\chi_{\text {cal }}^{2}$} & \multirow{2}{*}{$\chi_{\text {tab }}^{2}$} & \multirow{2}{*}{$\mathbf{P}$} \\
\hline & Yes & No & Total & & & & & \\
\hline Underweight & $189(56.4)$ & $138(43.6)$ & $335(100)$ & \multirow{6}{*}{5} & \multirow{6}{*}{0.14} & \multirow{6}{*}{29.07} & \multirow{6}{*}{11.07} & \multirow{6}{*}{0.000} \\
\hline Normal weight & $258(64.4)$ & $126(35.2)$ & $398(100)$ & & & & & \\
\hline Overweight & $247(68.4)$ & $129(31.6)$ & $361(100)$ & & & & & \\
\hline Class I Obesity & $178(74.5)$ & $55(25.5)$ & $239(100)$ & & & & & \\
\hline Class II Obesity & 95(77.9) & $40(22.1)$ & $122(100)$ & & & & & \\
\hline Class III Obesity & $53(81.5)$ & $12(18.5)$ & $65(100)$ & & & & & \\
\hline Total & $1020(67.1)$ & $500(32.9)$ & $1520(100)$ & & & & & \\
\hline
\end{tabular}

*Is the correlation coefficient

\subsection{Forms and degree of osteoarthritis pain reported by respondents}

Different people are living with different form of OA. As mentioned earlier, OA affects joints like knees hands, hips and spine. Table 7 indicates the forms and degree of OA pain reported by the population of people living with OA.

Table 7. Forms and Degree of Osteoarthritis Pain Reported by Respondents ( $\mathrm{n}=1120)$

\begin{tabular}{|l|c|c|c|c|c|c|}
\hline Joint Affected & Never & mild & moderate & severe & Very Severe & $* *$ Total Affected \\
\hline Knee & $11.80 \%$ & $24.50 \%$ & $18.50 \%$ & $21.60 \%$ & $23.60 \%$ & $88.20 \%$ \\
\hline Hand & $35.30 \%$ & $18.80 \%$ & $22.80 \%$ & $15.10 \%$ & $8.00 \%$ & $64.70 \%$ \\
\hline Hip & $72.00 \%$ & $15.40 \%$ & $10.90 \%$ & $1.00 \%$ & $0.70 \%$ & $28.00 \%$ \\
\hline Spine & $23.60 \%$ & $18.50 \%$ & $19.90 \%$ & $20.40 \%$ & $17.60 \%$ & $76.40 \%$ \\
\hline *Other & $88.80 \%$ & $6.40 \%$ & $3.60 \%$ & $0.90 \%$ & $0.30 \%$ & $11.20 \%$ \\
\hline
\end{tabular}

*Ankle, foot and Finger are included

$* *$ Never excluded

\section{Conclusion}

An empirical investigation into the prevalence of Osteoarthritis in south western states of Nigeria has been reported in this article. Among the 1800 questionnaires administered, only 1520 consisting of 700 males and 820 females were returned. The analysis carried out revealed that osteoarthritis is prevalent in south western states of Nigeria. $50.6 \%$ of the victims were males while $81.2 \%$ were females, this showed that 
osteoarthritis is more prevalent in females than males. Furthermore, $96 \%$ of the victims are above 60 years of age. This further showed that age is the greatest risk factor of osteoarthritis followed by occupation while BMI is the least. This correlate with the results reported in $[1,2,3,10]$ where age was reported to be the most prominent risk factor for osteoarthritis. Other risk factors such as BMI, previous history of osteoarthritis/hereditary and previous injuries were also studied. These are also responsible for osteoarthritis. Different joints such as kneel, hand, hip, spine ankle, foot, and fingers were also examined. Of these, analysis carried out showed that kneel is the leading cause of osteoarthritis experienced by Nigerians in south western states. Statistical analysis carried out revealed that there is significant association between all the risk factors examined and the prevalence of osteoarthritis in Nigeria.

\section{$5 \quad$ References}

[1] Loeser RF. Aging and osteoarthritis. Curr Opin Rheumatol 2011; 23: 492-496.

[2] Hügle, T., Geurts, J., Nüesch, C., Müller-Gerbl, M., \& Valderrabano, V. (2012). Aging and osteoarthritis: an inevitable encounter? Journal of aging research, 2012. https://doi.org/10. 1155/2012/950192.

[3] Chen, D., Shen, J., Zhao, W., Wang, T., Han, L., Hamilton, J. L., \& Im, H. J. (2017). Osteoarthritis: toward a comprehensive understanding of pathological mechanism. Bone research, 5, 16044.

[4] Slatkowsky-Christensen B, Mowinckel P, Kvien TK: Health status and perception of pain: a comparative study between female patients with hand osteoarthritis and rheumatoid arthritis. Scand. J. Rheumatol. 38, 342-348 (2009). https://doi.org/10.1080/030097409029 $\underline{13496}$

[5] Neogi, T., Nevitt, M.C., Yang, M., Curtis, J.R., Torner, J. and Felson, D.T., 2010. Consistency of knee pain: correlates and association with function. Osteoarthritis and cartilage, 18(10), pp.1250-1255. https://doi.org/10.1016/j.joca.2010.08.001

[6] Wise BL, Niu J, Zhang Y et al. Psychological factors and their relation to osteoarthritis pain. Osteoarthritis Cartilage.18, 883-887 (2010). https://doi.org/10.1016/j.joca.2009.11. $\underline{016}$

[7] Hayashi K, Kako M, Suzuki K, Hattori K, Fukuyasu S, Sato K, Kadono I, Sakai T, Hasegawa T, Nishida Y (2016). Gait Speeds Associated with Anxiety Responses to Pain in Osteoarthritis Patients. Pain. Med. 17(3):606-613. https://doi.org/10.1111/pme.12897

[8] Felson DT: Developments in the clinical understanding of osteoarthritis (2009). Arthritis Research \& Therapy, 11(1), 203-214

[9] Centers for disease control and prevention, 2017 online: https://www.cdc.gov/arthritis/ basics/osteoarthritis.htm accessed May 2018

[10] Palazzo, C., Ravaud, J. F., Papelard, A., Ravaud, P., \& Poiraudeau, S. (2014). The burden of musculoskeletal conditions. PloS one, 9(3), e90633. https://doi.org/10.1371/journal. pone.0090633

[11] Maetzel A, Li LC, Pencharz J, Tomlinson F, Bombardier C. The economic burden associated with osteoarthritis, rheumatic arthritis and hypertension: a comparative study. Ann. Rheum. Dis. 2004; p395 - 401 Vol. 63 (4). https://doi.org/10.1136/ard.2003.006031

[12] Zhang, W., Nuki, G., Moskowitz, R.W., Abramson, S., Altman, R.D., Arden, N.K., Bierma-Zeinstra, S., Brandt, K.D., Croft, P., Doherty, M. and Dougados, M., 2010. OARSI recommendations for the management of hip and knee osteoarthritis: part III: Changes in 
evidence following systematic cumulative update of research published through January 2009. Osteoarthritis and cartilage, 18(4), pp.476-499. https://doi.org/10.1016/j.joca.2010. $\underline{01.013}$

[13] Hunter D J, Schofiel D and Callander EJ (2014).The individual and socioeconomic impact of osteoarthritis Nature Reviews Rheumatology 10(7): 437-441) https://doi.org/10.1038/nr rheum.2014.44

[14] Blagojevic M, Jinks C, Jeffery A, Jordan KP. Risk factors for onset of osteoarthritis of the knee in older adults: a systematic review and meta-analysis. Osteoarthritis and cartilage, 2010, 18:24- 33. https://doi.org/10.1016/j.joca.2009.08.010

[15] Page CJ, Hinmam RS, Bennel KI (2011). Physiotherapy management of knee Osteoarthritis. Int . J. Rheumatic diseases 14(2): 145-151.

[16] Van Der Kraan, P.M., Berenbaum, F., Blanco, F.J., Lafeber, F., Hauge, E., Higginbottom, A., Ioan-Facsinay, A., Loughlin, J., Meulenbelt, I., Moilanen, E. and Pitsillidou, I., 2016. Translation of clinical problems in osteoarthritis into pathophysiological research goals. RMD open, 2(1), p.e000224. https://doi.org/10.1136/rmdopen-2015-000224

[17] Neogi T, Zhang Y. Epidemiology of osteoarthritis. Rheum Dis Clin North Am. 2013;39:119

[18] Arden N, Nevitt MC. Osteoarthritis: epidemiology. Best Pract Res Clin Rheumatol. 2006; 20:3-25.

[19] Mitsuyama H, Healey RM, Terkeltaub RA et al. Calcification of human articular knee cartilage is primarily an effect of aging rather than osteoarthritis. Osteoarthritis and Cartilage. 2007; p559 - 565 Vol. 15. https://doi.org/10.1016/j.joca.2006.10.017

[20] Kean WF, Kean R, Buchanan WW. Osteoarthritis: Symptoms signs and source of pain. Inflammo. Pharmacol. 2004; p3 - 31 Vol. 12. https://doi.org/10.1163/15685600477312134 7

[21] Anjum, Z., \& Abbas, S. R. (2015). Osteoarthritis, classification, prevalence and risk factors. Journal of Natural Sciences, 3, 6-10.

[22] Abhishek, A., \& Doherty, M. (2013). Diagnosis and clinical presentation of osteoarthritis. Rheumatic Disease Clinics, 39(1), 45-66.

[23] Akinpelu, AO; Alonge OO, Adekanla, BA and Odole, AC (2007). Pattern of Osteoarthritis Seen In Physiotherapy Facilities in Ibadan and Lagos, Nigeria. African Journal of Biomedical Research, 10: 111 - 115. https://doi.org/10.4314/ajbr.v10i2.50612

[24] Palazzo, C., Nguyen, C., Lefevre-Colau, M. M., Rannou, F., \& Poiraudeau, S. (2016). Risk factors and burden of osteoarthritis. Annals of physical and rehabilitation medicine, 59(3), 134-138. https://doi.org/10.1016/j.rehab.2016.01.006

[25] Johnson VL, Hunter DJ. The epidemiology of osteoart Allen, K. D., \& Golightly, Y. M. (2015). Epidemiology of osteoarthritis: state of the evidence. Current opinion in rheumatology, 27(3), 276.

[26] Srikanth VK, Fryer JL, Zhai G, Winzenberg TM, Hosmer D, Jones G. A meta - analysis of sex differences prevalence, incidence and severity of osteoarthritis. Osteoarthritis Cartilage 2005; 13(9):769-81. https://doi.org/10.1016/j.joca.2005.04.014

[27] Arellano, R.D.P.V., Argüello, J.R.A., Martínez, J.M., Marin, A.Y.G., Galarza, F.F.G., Guzman, D.G. and Sánchez, J.L.C., 2015. Brief Review of Genomics in Osteoarthritis. International Journal of Orthopaedics, 2(4), pp.341-346.

[28] Panoutsopoulou, K. and Zeggini, E., 2013. Advances in osteoarthritis genetics. Journal of medical genetics, 50(11), pp.715-724. https://doi.org/10.1136/jmedgenet-2013-101754

[29] Khan, H.I., Aitken, D., Chou, L., McBride, A., Ding, C., Blizzard, L., Pelletier, J.P., Pelletier, J.M., Cicuttini, F. and Jones, G., 2015. A family history of knee joint replacement increases the progression of knee radiographic osteoarthritis and medial tibial cartilage vol- 
ume loss over 10 years. Osteoarthritis and cartilage,23(2), pp.203-209. https ://doi.org/10.1016/j.joca.2014.11.016

[30] Pan, F., Ding, C., Winzenberg, T., Khan, H., Martel-Pelletier, J., Pelletier, J.P., Cicuttini, F. and Jones, G., 2016. The offspring of people with a total knee replacement for severe primary knee osteoarthritis have a higher risk of worsening knee pain over 8 years. Annals of the rheumatic diseases, 75(2), pp.368-373. https://doi.org/10.1136/annrheumdis-2014206005

[31] Jiang, L., X. Zhu, J. Rong, B. Xing, S. Wang, A. Liu, M. Chu, and G. Huang. "Obesity, osteoarthritis and genetic risk: The rs182052 polymorphism in the ADIPOQ gene is potentially associated with risk of knee osteoarthritis." Bone \& joint research 7, no. 7 (2018): 494-500. https://doi.org/10.1302/2046-3758.77.bjr-2017-0274.r1

[32] Jones, M. E., M. A. Davies, K. M. Leyland, A. Delmestri, A. Porter, J. Ratcliffe, N. Peirce, N. K. Arden, and J. L. Newton. "The association of previous injury with joint pain, osteoarthritis, and joint replacement across all joints in former elite english cricketers." Osteoarthritis and Cartilage 25 (2017): S200-S201. https://doi.org/10.1016/j. joca.2017.02.345

[33] Yucesoy, B., Charles, L.E., Baker, B. and Burchfiel, C.M., 2015. Occupational and genetic risk factors for osteoarthritis: a review. Work, 50(2), pp.261-273. https://doi.org/10.3233/ wor-131739

[34] Weiss, E., 2014. Knee osteoarthritis, body mass index and pain: data from the Osteoarthrtis Initiative. Rheumatology, 53(11),pp.2095099.https://doi.org/10.1093/rheumatology/keu244

[35] Zheng, H. and Chen, C., 2015. Body mass index and risk of knee osteoarthritis: systematic review and meta-analysis of prospective studies. BMJ open, 5(12), p.e007568. https://doi. org/10.1136/bmjopen-2014-007568

\section{Authors}

Aderonke Anthonia Kayode had B. Sc., M. Sc., and Ph. D. degrees in Computer Science. She is presently a lecturer in the Department of Computer Science, Landmark University, Omu-Aran, Nigeria. Dr. Kayode is a member of Computer Professional (Registration Council) of Nigeria (MCPN), Member, Nigeria Computer Society (MNCS), and Association for Computing Machinery (MACM). Her research areas include Data Mining, Health Informatics and Computational Intelligence.

Noah Oluwatobi Akande had B. Sc. and M. Sc. degrees in Computer Science from Ladoke Akintola University of Technology. He presently lectures in the Department of Computer Science, Landmark University, Omu-Aran, Nigeria. He is a member of Computer Professional (Registration Council) of Nigeria (MCPN), Member, Nigeria Computer Society (MNCS), and IAENG Society of Computer Science. His research areas include Data and Information Security and Pattern Recognition (Medical Image Analysis). akande.noah@lmu.edu.ng

Saheed Olalekan Jabaru has B. Sc. and M. Sc. degrees in Statistics. He is a lecturer in Alhikmah University, Ilorin, Nigeria. His research interests include applied statistics and operation research. Mr Jabaru is a member of Nigeria Statistical Association and Professional Statisticians Society of Nigeria.

Tinuke Omolewa Oladele is a Senior Lecturer in the Department of Computer Science, Faculty of Communication and Information Sciences, University of Ilorin, 
Ilorin, Nigeria. She obtained her B.Sc. in Computer Science from the University of Benin, Benin City, Edo State. She bagged her M. Sc in Mathematics (Computer Science Option) from the University of Ilorin and a Ph.D. in Computer Science also from the University of Ilorin. She is known across board for her innovative research work in Bioinformatics and Computational Biology. Her research interests include Artificial Intelligence, Data Mining, and Cyber Security.

Article submitted 2019-08-21. Resubmitted 2019-09-20. Final acceptance 2019-09-21. Final version published as submitted by the authors. 